\title{
Genetic Predictors of Type 2 Diabetes in Yakuts
}

\author{
Nadezhda I. Pavlova ${ }^{1 *}$, PhD; Aleksandra T. Diakonova ${ }^{1}$; Vladislav A. Alekseev"; \\ Lyubovy A. Sydykova ${ }^{2}, \mathrm{PhD}$; Nadezhda E. Maksimova ${ }^{3}$; Zoya A. Rudykh ${ }^{3}$; \\ Yana V. Chertovskikh ${ }^{3}$; Dmitry A. Sychev ${ }^{4}, \mathrm{PhD}, \mathrm{ScD}$; Vladimir V. Dodokhov ${ }^{5}, \mathrm{PhD}$; \\ Tuyara I. Dmitrieva ${ }^{5}$ Khariton A. Kurtanov ${ }^{6}, \mathrm{PhD}$ \\ ${ }^{I}$ Yakut Science Center of Complex Medical Problems, Yakutsk, Russia \\ ${ }^{2}$ M. K. Ammosov North-Eastern Federal University, Yakutsk, Russia \\ ${ }^{3}$ Center for Personalized Medicine, Republican Clinical Hospital No. 3, Yakutsk, Russia \\ ${ }^{4}$ Russian Medical Academy of Continuing Professional Education, Moscow Russia \\ ${ }^{5}$ Arctic State Agrotechnological University, Yakutsk, Russia \\ ${ }^{6}$ Institute for Biological Problems of Cryolithozone of SB of RAS, Yakutsk, Russia
}

\begin{abstract}
The goal of this study was to investigate the distribution of alleles and genotypes of the KCNJ11 rs5219, PPARG rs1801282, TCF7L2 rs7903146/rs12255372 SNPs in Yakuts with T2D, in comparison with other ethnic populations.

Methods and Results: The study cohort consisted of 26 Yakut patients diagnosed with T2D (YKT2D). Genotyping of rs5219 (KCNJ11), rs1801282 (PPARG), rs7903146 and rs12255372 (TCF7L2) SNPs was performed by pyrosequencing using PyroMark Q48 Autoprep sequencer (QIAGEN).

The genotyping of the studied group of Yakuts did not reveal statistically significant differences between control groups and YKT2D patients with respect to the polymorphic variants of the KCNJ11, PPARG, and TCF7L2 genes. The allele frequency analysis of the polymorphisms of the KCNJ11, PPARG, and TCF7L2 genes demonstrated a low frequency of the risk T-allele in the TCF7L2 (rs7903146, rs 12255372) in Asian populations, compared to other human populations. We identified three haplotypes [CG (90.5\%), TT (6.8\%), and TG (2.7\%)] in the YKT2D cohort. Also, we observed a strong LD between two SNPs (rs7903146 and rs12255372) of the TCF7L2 gene in the majority of groups, including YKT2D ( $\left.{ }^{\prime}=1, \mathrm{LOD}=4.92\right)$, except for African populations, where a very weak LD ( $\left.{ }^{`}=0.001-0.435, \mathrm{LOD}=0.0-0.73\right)$ was observed.(International Journal of Biomedicine. 2021;11(3):355-360.)
\end{abstract}

Key Words: $K C N J 11 \cdot P P A R G \bullet T C F 7 L 2 \cdot$ type 2 diabetes $\bullet$ single nucleotide polymorphism

For citation: Pavlova NI, Diakonova AT, Alekseev VA, Sydykova LA, Maksimova NE, Rudykh ZA, Chertovskikh YaV, Sychev DA, Dodokhov VV, Dmitrieva TI, Kurtanov KhA. Genetic Predictors of Type 2 Diabetes in Yakuts. International Journal of Biomedicine. 2021;11(3):355-360. doi:10.21103/Article11(3)_OA13

\section{Abbreviations}

GWAS, genome-wide association studies; HWE, Hardy-Weinberg equilibrium; KATP, adenosine triphosphate (ATP)-sensitive potassium channel; KCNJ11, potassium inwardly rectifying channel, subfamily J, member 11; LD, linkage disequilibrium; PPARG, peroxisome proliferator-activated receptor gamma; SNPs, single nucleotide polymorphisms; T2D, type 2 diabetes; TCF7L2, transcription factor-7-like 2.

\section{Introduction}

Type 2 diabetes (T2D) is characterized by insulin resistance and/or insufficient insulin production by $\beta$-cells. ${ }^{(1)}$ T2D is believed to be a polygenic disorder that results from a complex interaction of many genes and environmental factors. SNPs are now well recognized as the most popular molecular markers for genetic studies. SNPs are the most common genetic variation; they occur, on average, once in every $400-1,000$ base pairs along DNA. ${ }^{(2-5)}$ To date, GWAS 
have discovered $>600$ genetic variants associated with T2D.(6) Multiple genes and their interactions are involved in the insulin secretion pathway. The glucose-dependent insulin secretion in $\beta$-cells of the pancreas is regulated by KATP. KATP is a heteromeric protein, composed of four inwardrectifier potassium ion channel (Kir6.2) tetramers, which form the pore of the KATP channel, as well as sulfonylurea receptor 1 subunits surrounding the pore. Kir6.2 is encoded by the KCNJ11 gene- a member of the potassium channel genes. Closure of ATP-regulated $\mathrm{K}+$ channels (KATP channels) plays a central role in glucose-stimulated insulin secretion in $\beta$-cells. ${ }^{(7)}$ Numerous studies have reported the involvement of SNPs of the KCNJ11 gene and their interactions in the susceptibility to diabetes. KCNJ11 rs5219 is a common variant in which substitution of $\mathrm{C}$ to $\mathrm{T}$ replaces glutamate with lysine at position 23 (E23K) in exon 1, causing a decrease of insulin secretion. Among the SNPs in the $K C N J 11$ gene, rs5219 is associated with an increased risk for T2D in various populations. ${ }^{(7-9)}$

The PPARG gene is located on chromosome 3p25 and plays a critical role in adipose tissue formation and subcellular metabolism of arterial wall macrophage foam cells. PPARG controls insulin sensitivity by transcriptionally stimulating adipocyte-specific genes involved in insulin signaling, lipid accumulation, fatty acid uptake, and glucose uptake. The $P P A R G$ rs $1801282 \mathrm{C}>\mathrm{G}$ polymorphism, an SNP in exon 2 of PPAR- $\gamma$, encodes a proline $\rightarrow$ alanine substitution at amino acid residue 12. This mutation reduces the transcription of $P P A R G$. The $P P A R G$ rs $1801282 \mathrm{C}>\mathrm{G}$ polymorphism has been extensively investigated and was found to be correlated with the risk of cardiovascular diseases and T2D. ${ }^{(10)}$

The TCF7L2 gene is responsible for the synthesis of a transcription factor 7-like 2, which regulates the expression of the proglucagon gene and other genes involved in carbohydrate metabolism. The TCF7L2 gene is localized on chromosome 10q25.3. The risk T-allele of the TCF7L2 rs7903146 SNP is associated with increased TCF7L2 expression, and decreased insulin content and secretion(11). Risk T-allele carriers are further characterized by an elevated plasma proinsulin level and an increased proinsulin-to-insulin ratio suggestive of perturbed proinsulin processing. ${ }^{(11-15)}$ The rs12255372 SNP, located in the intron region of $T C F 7 L 2$, contains a single base $\mathrm{G}$ to $\mathrm{T}$ transition at position 293. A few epidemiological studies have assessed the relationship between rs12255372 and T2D, but the results of these studies are contradictory. ${ }^{(16-21)}$

According to previous studies on the Yakut populations, the most significant variants involved in the development of T2D were identified in the $A B C C 8$ gene (rs1799859 SNP and rs10811661 SNP), $L P L$ gene (Int6/PvuII G $>$ A and Int8/Hind3 variants), and $R S T N$ gene (CDKN2A/B rs34861192 SNP and rs32119177 SNP). There were no statistically significant differences between the control groups and patients with T2D with respect to the polymorphic variants of the TCF $7 L 2$ and KCNJ11 genes. ${ }^{(22)}$

The goal of this study was to investigate the distribution of alleles and genotypes of the KCNJ11 rs5219, PPARG rs1801282, TCF7L2 rs7903146/rs12255372 SNPs in Yakuts with $\mathrm{T} 2 \mathrm{D}$, in comparison with other ethnic populations.

\section{Materials and Methods}

The study cohort consisted of 26 Yakut patients diagnosed with T2D (YKT2D). Exclusion criteria were other types of diabetes, low fasting insulin levels, cancer, heart failure (NYHA class III-IV), concomitant corticosteroid or estrogen treatment, alcoholism, drug addiction, dementia, and serious mental disorders. The reference group was a cohort of different populations without T2D, obtained from the 1000 Genomes Project database and other sources.

Genotyping of rs5219 (KCNJ11), rs1801282 (PPARG), rs7903146 and rs12255372 (TCF7L2) SNPs was performed by pyrosequencing using PyroMark Q48 Autoprep sequencer (QIAGEN).

The study was approved by the Ethics Committee of the Center for Personalized Medicine at the Republican Clinical Hospital No. 3. Written informed consent was obtained from each research participant (or the participant's parent/guardian).

Statistical analysis was performed using Microsoft Excel 2010.and PASW Statistics 18. The correspondence of the distributions of genotypes to the expected values at HWE and comparison of the frequencies of allelic variants/ genotypes were performed using the chi-square test. Haploview software (ver. 4.2) was used to assess the TCF7L2 haplotypes and frequencies based on genotyping data and to test the association between alleles and haplotypes of the TCF7L2 gene. ${ }^{(23)}$ A probability value of $P<0.05$ was considered statistically significant.

\section{Results and Discussion}

The results of this study show that the distribution of genotypes for all studied SNPs do not have significant deviations from the HWE. Comparative analysis of allele and genotype frequency distribution in the examined group is presented in Table 1.

Table 1.

Distribution of alleles and genotypes of polymorphisms of genes KCNJ11, PPARG, and TCF7L2 in a group of Yakut patients with T2D

\begin{tabular}{|c|c|c|c|c|c|c|c|c|}
\hline $\begin{array}{c}\text { Gene } \\
\text { (RefSNP) }\end{array}$ & Dis & & enoty & & All & eles & $\gamma^{2}$ & P \\
\hline & & $\mathrm{CC}$ & $\mathrm{CT}$ & TT & $\mathrm{C}$ & $\mathrm{T}$ & & \\
\hline $\begin{array}{l}K C N J 11 \\
(\mathbf{r} 5219)\end{array}$ & OF & 42.3 & 46.2 & 11.5 & & & & \\
\hline & $\mathrm{EF}$ & 42.8 & 45.3 & 12.0 & 0.054 & 0.340 & 0.010 & 0.924 \\
\hline & & $\mathrm{CC}$ & CG & GG & $\mathrm{C}$ & $\mathrm{G}$ & $\chi^{2}$ & $\mathrm{P}$ \\
\hline $\begin{array}{l}P P A R G \\
(\text { rs } 1801282)\end{array}$ & $\mathrm{OF}$ & 65.4 & 30.8 & 3.8 & one & 0.107 & 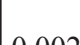 & 006 \\
\hline & $\mathrm{EF}$ & 65.2 & 31.1 & 3.7 & J & 0.192 & 0.002 & 0.901 \\
\hline & & $\mathrm{CC}$ & $\mathrm{CT}$ & TT & $\mathrm{C}$ & $\mathrm{T}$ & $\chi^{2}$ & $\mathrm{P}$ \\
\hline $\begin{array}{l}\text { TCF7L2 } \\
\text { (rs7903146) }\end{array}$ & OF & 92.3 & 7.7 & 0.0 & & & & 0.028 \\
\hline & EF & 92.5 & 7.4 & 0.1 & 0.902 & 000 & 0.042 & 0.050 \\
\hline & & GG & GT & TT & G & $\mathrm{T}$ & $\chi^{2}$ & $\mathrm{P}$ \\
\hline $\begin{array}{l}\text { TCF7L2 } \\
\text { (rs12255372) }\end{array}$ & $\mathrm{OF}$ & 96.15 & 3.85 & 0.00 & & 010 & $\Omega_{-1}$ & 0 \\
\hline & $\mathrm{EF}$ & 96.19 & 3.77 & 0.04 & 0.5 & 0.019 & 0.010 & 0.920 \\
\hline
\end{tabular}

Dis-distribution, OF- observed frequency, EF- expected frequency 
An analysis of the frequency distribution of alleles and genotypes of the KCNJ11 rs5219 SNP in a sample of YKT2D revealed the predominance of the heterozygous CT genotype (46.2\%); the TT genotype (11.5\%) was less common. Several meta-analyses and association studies reported a strong association between the r5219 (KCNJ11 E23K) and susceptibility to T2D, mainly in Caucasians and in some Asian populations. ${ }^{(24-26)}$ However, some other association studies did not show any association between this polymorphism and susceptibility to T2D. ${ }^{(27)}$
The study of the PPARG rs 1801282 showed the prevalence of the CC genotype (65.4\%), while the frequency of the GG genotype was $3.8 \%$. The $P P A R G \mathrm{rs} 1801282 \mathrm{C}>\mathrm{G}$ polymorphism has been extensively studied and found to correlate with the risk of cardiovascular disease and T2D. ${ }^{(28-31)}$ However, other studies reported contradictory results. ${ }^{(32)}$ For example, it was shown that the Pro12Ala polymorphism protects against diabetes in Caucasians, but not in the South Asian population. ${ }^{(3-33)}$

The TCF7L2 rs7903146 SNP was characterized by the prevalence of the CC genotype $(92.3 \%)$, while the TT

Table 2.

Frequency of risk alleles in KCNJ11, PPARG and TCF7L2 gene polymorphisms in the cohort of Yakuts with T2D and other ethnic populations

\begin{tabular}{|c|c|c|c|c|c|}
\hline \multirow{4}{*}{ Group } & \multicolumn{4}{|c|}{ Genes and polymorphisms } & \multirow{4}{*}{ Reference } \\
\hline & KCNJ11 & PPARG & \multicolumn{2}{|c|}{ TCF7L2 } & \\
\hline & rs5219 & rs1801282 & rs7903146 & rs 12255372 & \\
\hline & $\mathrm{T}$ & $\mathrm{G}$ & $\mathrm{T}$ & $\mathrm{T}$ & \\
\hline YKT2D & $34.6(26)$ & $19.2(26)$ & $3.8(26)$ & $1.9(26)$ & - \\
\hline YKTH & $33(348)$ & $15(348)$ & $5(348)$ & Without data & {$[35]$} \\
\hline RUS & $43.9(264)$ & $20.7(94)$ & $27.6(201)$ & $16.1(597)$ & {$[27-40]$} \\
\hline KGZ & $33(109)$ & $13(109)$ & $11(109)$ & Without data & [36] \\
\hline JPN & $33(104)$ & $3(104)$ & $3(104)$ & $2(104)$ & \\
\hline CDX & $22.6(93)$ & $0.5(93)$ & $2.2(93)$ & $1.1(93)$ & \\
\hline GBR & $26.4(48)$ & $12.1(22)$ & $25.8(47)$ & $26.4(48)$ & \\
\hline IBS & $38.3(82)$ & $11.7(22)$ & $39.7(85)$ & $37.4(80)$ & \\
\hline PEL & $32(85)$ & $26(85)$ & $14(85)$ & $11(85)$ & \\
\hline PJL & $44(96)$ & $14(96)$ & $25(96)$ & $21(96)$ & \\
\hline STU & $30.4(62)$ & $12.3(25)$ & $33.8(69)$ & $22.1(45)$ & [23] \\
\hline MSL & 0 & 0 & $22.9(39)$ & $38.8(66)$ & \\
\hline YRI & 0 & 0 & $24.1(52)$ & $30.1(65)$ & \\
\hline ACB & $5.7(11)$ & $1.6(3)$ & $27.6(53)$ & $24.5(47)$ & \\
\hline ASW & $13.9(17)$ & $2.5(3)$ & $36.1(44)$ & $27 / 9(34)$ & \\
\hline ESN & 0 & 0 & $24.7(49)$ & $29.3(58)$ & \\
\hline
\end{tabular}

Abbreviations: YKT2D - Yakuts patients with T2D; YKTH - healthy Yakuts without T2D; RUS - healthy Russians; KGZ - healthy Kyrgyz; ACB - African Caribbean in Barbados; ASW - African Ancestry in Southwest US; CDX - Chinese Dai in Xishuangbanna, China; ESN - Esan in Nigeria; GBR - British in England and Scotland; GWD - Gambian in Western Division, The Gambia; IBS - Iberian populations in Spain; JPT - Japanese in Tokyo, Japan; MSL - Mende in Sierra Leone; MXL - Mexican Ancestry in Los Angeles, California; PEL - Peruvian in Lima, Peru; PJL - Punjabi in Lahore, Pakistan; STU - Sri Lankan Tamil in the UK; YRI - Yoruba in Ibadan, Nigeria.

Table 3.

The frequency distribution of TCF7L2 gene haplotypes for two SNPs (rs7903146 and rs12255372) in Yakuts with T2D and other ethnic populations

\begin{tabular}{|l|c|c|c|c|c|c|c|}
\hline \multirow{2}{*}{ Group } & \multicolumn{4}{|c|}{ Haplotype } & \multicolumn{2}{c|}{ Linkage disequilibrium (LD) } & \multirow{2}{*}{ Reference } \\
\cline { 2 - 7 } & CG & CT & TT & TG & D' & LOD & - \\
\hline YKT2D & 90.5 & - & 6.8 & 2.7 & 1.0 & 4.92 & 5.24 \\
\hline JPN & 96.6 & 0.5 & 1.9 & 1.0 & 0.793 & 2.99 \\
\hline CDX & 97.8 & - & 1.1 & 1.1 & 1.0 & 26.94 \\
\hline GBR & 73.1 & 1.1 & 25.3 & 0.6 & 0.971 & 27.02 \\
\hline IBS & 58.8 & 1.5 & 35.0 & 4.7 & 0.933 & 14.89 \\
\hline PEL & 86.5 & - & 10.6 & 2.9 & 1.0 & 12.11 \\
\hline MXL & 76.5 & 1.6 & 17.9 & 4.0 & 0.893 & 0.966 & 21.95 \\
\hline PJL & 74.5 & 0.5 & 20.8 & 4.2 & 13.77 \\
\hline STU & 65.0 & 0.11 & 20.9 & 12.9 & 0.923 & 0.26 \\
\hline MSL & 49.9 & 27.2 & 11.6 & 11.3 & 0.193 & 0.27 \\
\hline YRI & 50.9 & 25.0 & 5.1 & 19.0 & 0.296 & 0.0 \\
\hline ACB & 54.7 & 17.7 & 6.8 & 20.8 & 0.001 & 0.0 \\
\hline ASW & 45.7 & 18.2 & 9.7 & 26.4 & 0.039 & 0.73 \\
\hline ESN & 50.1 & 25.2 & 0.41 & 20.7 & 0.435 & 0.119 & 0.22 \\
\hline GWD & 50.5 & 26.5 & 10.2 & 12.8 & 0.19 & \\
\hline
\end{tabular}

Abbreviations: (see Table 2). 
genotype was not found in the studied group. The TCF 2 2 2 rs 12255372 was characterized by the predominance of the GG genotype (96.1\%) and the absence of the TT genotype.

The comparative analysis of risk allele frequencies in KCNJ11, PPARG, and TCF7L2 gene polymorphisms in the studied group and other ethnic populations is presented in Table 2.

The allele frequency analysis showed a low frequency of the risk T-allele of the TCF7L2 (rs7903146 and rs12255372) SNPs in Asian populations, compared to other ethnic groups (Yakuts without T2D - 3.8\% and 1.9\%, Kyrgyz - 11\%, Japanese $-3 \%$ and $2 \%$, Han Chinese from southern regions of China $-2.2 \%$ and $1.1 \%$ ). The frequency of the risk $\mathrm{T}$ allele of the TCF7L2 rs7903146 SNP (3.8\%) in the studied YKT2D cohort was similar to the frequency of the T allele in Yakuts without T2D (5\%). Probably, the low frequency of the risk T allele in rs7903146, rs12255372 SNPs in Asian populations contributes to the low incidence of T2D.

There was a strong LD between two SNPs (rs7903146 and rs12255372) of the TCF7L2 gene (Fig. 1 and Table 3) in almost all groups, including YKT2D $(\mathrm{D} '=1, \mathrm{LOD}=4.92)$, except for African populations, where a very weak LD (D ' $=$ $0.001-0.435, \mathrm{LOD}=0.0-0.73$ ) was observed. This is likely due to a high genetic diversity in African populations. This can also indicate that the ancient humans that left the African continent and settled in Europe, Asia, and America went through a strong population decline, the so-called "bottleneck." And our results can indirectly confirm that the division of the human race into Mongoloid and Caucasian races occurred after the exodus from Africa.

The frequency distribution of TCF $7 L 2$ gene haplotypes for two SNPs (rs7903146 and rs12255372) based on all detected variants is presented in Table 3 . There are four possible haplotypes CG, CT, TT, and TG for rs7903146 and rs 12255372 polymorphisms. We were able to identify three haplotypes [CG(90.5\%), $\mathrm{TT}(6.8 \%)$, and $\mathrm{TG}(2.7 \%)]$ in the studied YKT2D group. These haplotypes were also found in the Chinese population and Peruvians. A similar haplotype frequency was observed in Peruvians $[\mathrm{CG}(86.5 \%)$, $\mathrm{TT}(10.6 \%)$, and TG(2.9\%)]. We also observed a low frequency of haplotypes with the risk $\mathrm{T}$ allele in Yakuts, Chinese and Japanese people, and the absence of a heterozygous CT haplotype in Yakuts and Chinese (Table 3).

In conclusion, the genotyping of the studied group of Yakuts did not reveal statistically significant differences between control groups and YKT2D patients with respect to the polymorphic variants of the KCNJ11, PPARG, and TCF7L2 genes. The allele frequency analysis of the polymorphisms of the KCNJ11, PPARG, and TCF7L2 genes demonstrated a low frequency of the risk T-allele in the TCF7L2 (rs7903146, rs12255372) in Asian populations, compared to other human populations. We identified three haplotypes $[\mathrm{CG}(90.5 \%)$, $\mathrm{TT}(6.8 \%)$, and $\mathrm{TG}(2.7 \%)]$ in the YKT2D cohort. Also, we observed a strong LD between two SNPs (rs7903146 and rs12255372) of the TCF7L2 gene in the majority of groups, including YKT2D ( $\left.{ }^{\prime}=1, \mathrm{LOD}=4.92\right)$, except for African populations, where a very weak LD ( $\mathrm{D}^{\prime}=0.001-0.435$, LOD $=0.0-0.73$ ) was observed.
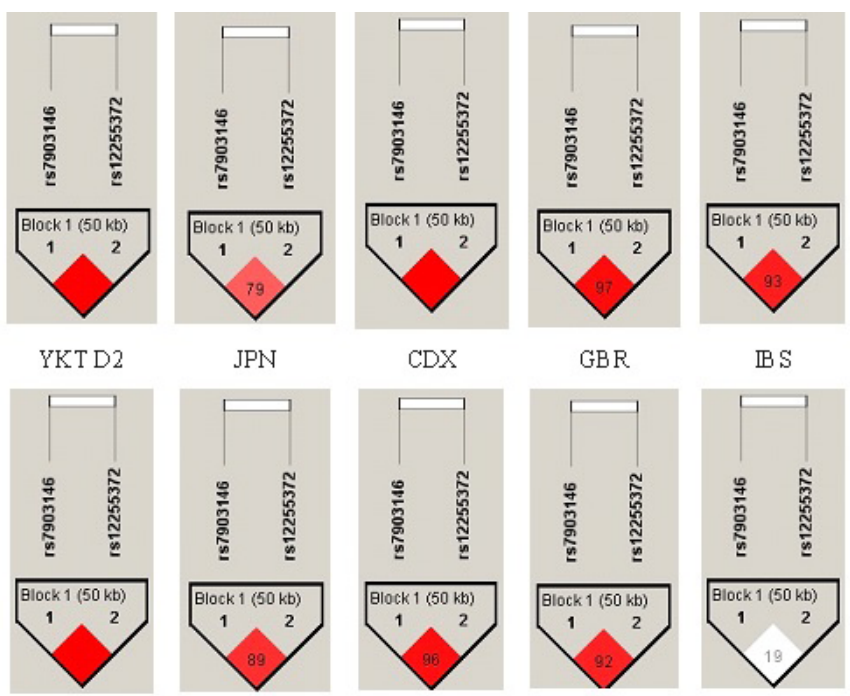

JPN

CDX
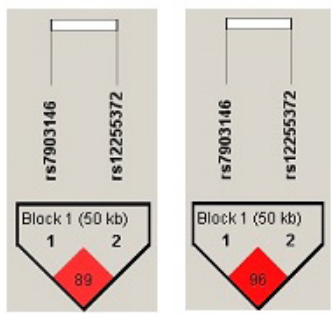

GBR

$\mathbb{B} S$

PEL

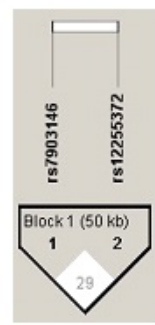

MXL

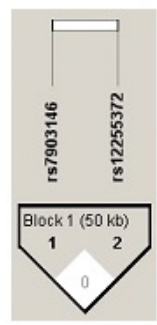

$\mathrm{ACB}$
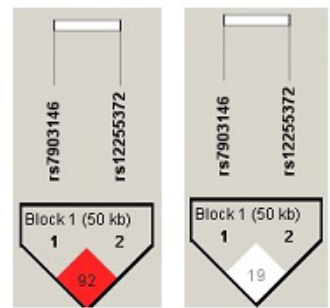

PJL

STU

MSL

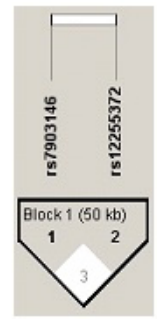

ASW
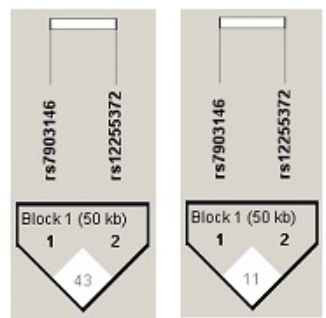

ESN

GWD

Fig. 1. LD between the TCF7L2 (rs7903146, rs 12255372) SNPs

The color scheme shows the strength of adhesion between SNPs: bright red - a strong link $\left(D^{\prime}=1, L O D=2\right)$, pink-red - a significant $\operatorname{link}\left(D^{\prime}<1, L O D=2\right)$, white - poor link $\left(D^{\prime}<1, L O D<2\right)$.

Abbreviations: YKT2D - Yakuts patients with T2D; ACB - African Caribbean in Barbados; ASW - African Ancestry in Southwest US; CDX - Chinese Dai in Xishuangbanna, China; ESN - Esan in Nigeria; GBR - British in England and Scotland; GWD - Gambian in Western Division. The Gambia: IBS - Iberian populations in Spain: JPT - Japanese in Tokyo, Japan; MSL - Mende in Sierra Leone; MXL - Mexican Ancestry in Los Angeles, California; PEL - Peruvian in Lima, Peru; PJL - Punjabi in Lahore, Pakistan; STU - Sri Lankan Tamil in the UK; YRI - Yoruba in Ibadan, Nigeria.

\section{Competing Interests}

The authors declare that they have no competing interests.

\section{References}

1. Taylor R. Type 2 diabetes: etiology and reversibility. Diabetes Care. 2013 Apr;36(4):1047-55. doi: 10.2337/dc121805.

2. Gray IC, Campbell DA, Spurr NK. Single nucleotide polymorphisms as tools in human genetics. Hum Mol Genet. 2000 Oct;9(16):2403-8. doi: 10.1093/hmg/9.16.2403.

*Corresponding author: Nadezhda I. Pavlova, PhD. Yakut Science Center of Complex Medical Problems. Yakutsk, the Republic of Sakha (Yakutia), Russia.E-mail: solnishko_84@inbox.ru 
3. Miller RD, Kwok PY. The birth and death of human singlenucleotide polymorphisms: new experimental evidence and implications for human history and medicine. Hum Mol Genet. 2001 Oct 1;10(20):2195-8. doi: 10.1093/hmg/10.20.2195.

4. Taylor JG, Choi EH, Foster CB, Chanock SJ. Using genetic variation to study human disease. Trends Mol Med. 2001 Nov;7(11):507-12. doi: 10.1016/s1471-4914(01)02183-9. 5. Shastry BS. SNP alleles in human disease and evolution. J Hum Genet. 2002;47(11):561-6. doi: 10.1007/s100380200086. 6. Vujkovic M, Keaton JM, Lynch JA, Miller DR, Zhou J, Tcheandjieu C, et al. Discovery of 318 new risk loci for type 2 diabetes and related vascular outcomes among 1.4 million participants in a multi-ancestry meta-analysis. Nat Genet. 2020 Jul;52(7):680-691. doi: 10.1038/s41588-020-0637-y.

7. Haghvirdizadeh P, Mohamed Z, Abdullah NA, Haghvirdizadeh P, Haerian MS, Haerian BS. KCNJ11: Genetic Polymorphisms and Risk of Diabetes Mellitus. J Diabetes Res. 2015;2015:908152. doi: 10.1155/2015/908152.

8. Koo BK, Cho YM, Park BL, Cheong HS, Shin HD, Jang HC, et al. Polymorphisms of KCNJ11 (Kir6.2 gene) are associated with Type 2 diabetes and hypertension in the Korean population. Diabet Med. 2007 Feb;24(2):178-86. doi: 10.1111/j.1464-5491.2006.02050.x.

9. Abdelhamid I, Lasram K, Meiloud G, Ben Halim N, Kefi $\mathrm{R}$, Samb A, et al. E23K variant in KCNJ11 gene is associated with susceptibility to type 2 diabetes in the Mauritanian population. Prim Care Diabetes. 2014 Jul;8(2):171-5. doi: 10.1016/j.pcd.2013.10.006.

10. Hasan NS, Kamel SA, Hamed M, Awadallah E, Rahman AHA, Musa NI, Hussein GHS. Peroxisome proliferatoractivated receptor- $\gamma$ polymorphism (rs 1801282) is associated with obesity in Egyptian patients with coronary artery disease and type 2 diabetes mellitus. J Genet Eng Biotechnol. 2017 Dec;15(2):409-414. doi: 10.1016/j.jgeb.2017.08.002.

11. Zhou Y, Park SY, Su J, Bailey K, Ottosson-Laakso E, Shcherbina L, et al. TCF7L2 is a master regulator of insulin production and processing. Hum Mol Genet. 2014 Dec 15;23(24):6419-31. doi: 10.1093/hmg/ddu359.

12. Dahlgren A, Zethelius B, Jensevik K, Syvänen AC, Berne C. Variants of the TCF7L2 gene are associated with beta cell dysfunction and confer an increased risk of type 2 diabetes mellitus in the ULSAM cohort of Swedish elderly men. Diabetologia. 2007 Sep;50(9):1852. doi: 10.1007/s00125007-0746-5.

13. González-Sánchez JL, Martínez-Larrad MT, Zabena C, Pérez-Barba M, Serrano-Ríos M. Association of variants of the TCF7L2 gene with increases in the risk of type 2 diabetes and the proinsulin:insulin ratio in the Spanish population. Diabetologia. 2008 Nov;51(11):1993-7. doi: 10.1007/s00125008-1129-2.

14. Kirchhoff K, Machicao F, Haupt A, Schäfer SA, Tschritter $\mathrm{O}$, Staiger H, et al. Polymorphisms in the TCF7L2, CDKAL1 and SLC30A8 genes are associated with impaired proinsulin conversion. Diabetologia. 2008 Apr;51(4):597-601. doi: 10.1007/s00125-008-0926-y.

15. Silbernagel G, Renner W, Grammer TB, Hügl SR, Bertram J, Kleber ME, et al. Association of TCF7L2 SNPs with age at onset of type 2 diabetes and proinsulin/insulin ratio but not with glucagon-like peptide 1. Diabetes Metab Res Rev. 2011 Jul;27(5):499-505. doi: 10.1002/dmrr.1194.

16. Ciccacci C, Di Fusco D, Cacciotti L, Morganti R, D'Amato C, Novelli G, et al. TCF7L2 gene polymorphisms and type 2 diabetes: association with diabetic retinopathy and cardiovascular autonomic neuropathy. Acta Diabetol. 2013 Oct;50(5):789-99. doi: 10.1007/s00592-012-0418-X.

17. Ren Q, Han XY, Wang F, Zhang XY, Han LC, Luo YY, Zhou XH, Ji LN. Exon sequencing and association analysis of polymorphisms in TCF7L2 with type 2 diabetes in a Chinese population. Diabetologia. 2008 Jul;51(7):1146-52. doi: 10.1007/s00125-008-1039-3.

18. Miyake K, Horikawa Y, Hara K, Yasuda K, Osawa H, Furuta H, et al. Association of TCF7L2 polymorphisms with susceptibility to type 2 diabetes in 4,087 Japanese subjects. J Hum Genet. 2008;53(2):174-180. doi: 10.1007/s10038-0070231-5.

19. Bodhini D, Radha V, Dhar M, Narayani N, Mohan V. The rs12255372(G/T) and rs7903146(C/T) polymorphisms of the TCF7L2 gene are associated with type 2 diabetes mellitus in Asian Indians. Metabolism. 2007 Sep;56(9):1174-8. doi: 10.1016/j.metabol.2007.04.012.

20. Sale MM, Smith SG, Mychaleckyj JC, Keene KL, Langefeld CD, Leak TS, et al. Variants of the transcription factor 7-like 2 (TCF7L2) gene are associated with type 2 diabetes in an African-American population enriched for nephropathy. Diabetes. 2007 Oct;56(10):2638-42. doi: 10.2337/db07-0012.

21. Grant SF, Thorleifsson G, Reynisdottir I, Benediktsson R, Manolescu A, Sainz J, et al. Variant of transcription factor 7-like 2 (TCF7L2) gene confers risk of type 2 diabetes. Nat Genet. 2006 Mar;38(3):320-3. doi: 10.1038/ng1732.

22. Ignatiev PM. Epidemic of type 2 diabetes in the world and in the Republic of Sakha (Yakutia). Novosibirsk: Izd. Nauka, 2011. [In Russian].

23. HAPLOVIEW v.4.2 [Internet]. Available from: http:// www.broadinstitute.org/scientific-community/science/ programs/medical-and-population-genetics/haploview/ haploview

24. Gonen MS, Arikoglu H, Erkoc Kaya D, Ozdemir H, Ipekci SH, Arslan A, Kayis SA, Gogebakan B. Effects of single nucleotide polymorphisms in K(ATP) channel genes on type 2 diabetes in a Turkish population. Arch Med Res. 2012 May;43(4):317-23. doi: 10.1016/j.arcmed.2012.06.001.

25. He YY, Zhang R, Shao XY, Hu C, Wang CR, Lu JX, et al. Association of KCNJ11 and ABCC8 genetic polymorphisms with response to repaglinide in Chinese diabetic patients. Acta Pharmacol Sin. 2008 Aug;29(8):983-9. doi: 10.1111/j.17457254.2008.00840.x.

26. Chistiakov DA, Potapov VA, Khodirev DC, Shamkhalova MS, Shestakova MV, Nosikov VV. Genetic variations in the pancreatic ATP-sensitive potassium channel, beta-cell dysfunction, and susceptibility to type 2 diabetes. Acta Diabetol. 2009 Mar;46(1):43-9. doi: 10.1007/s00592-0080056-5.

27. Godwill Azeh Engwa, Friday Nweke Nwalo, Chosen E. Obi, Christie Onyia, Opeolu Oyejide Ojo, Wilfred Fon Mbacham, Benjamin Ewa Ubi. Predominance of the A allele but no association of the KCNJ11 rs5219 E23K polymorphism with Type 2 Diabetes in a Nigerian population. Genet. Mol. Res. 2018;17(1); gmr16039889 doi: 10.4238/gmr16039889 28. Wang X, Liu J, Ouyang Y, Fang M, Gao H, Liu L. The association between the Pro12Ala variant in the PPAR $\gamma 2$ gene and type 2 diabetes mellitus and obesity in a Chinese population. PLoS One. 2013 Aug 21;8(8):e71985. doi: 10.1371/journal.pone.0071985.

29. Li Y, Dai L, Zhang J, Wang P, Chai Y, Ye H, et al. Cyclooxygenase-2 polymorphisms and the risk of gastric 
cancer in various degrees of relationship in the Chinese Han population. Oncol Lett. 2012 Jan;3(1):107-112. doi: 10.3892/ ol.2011.426.

30. Youssef SM, Mohamed N, Afef S, Khaldoun BH, Fadoua N, Fadhel NM, Naceur SM. A Pro 12 Ala substitution in the PPAR $\gamma 2$ polymorphism may decrease the number of diseased vessels and the severity of angiographic coronary artery. Coron Artery Dis. 2013 Aug;24(5):347-51. doi: 10.1097/ MCA.0b013e328361a95e.

31. LwowF, Dunajska K, MilewiczA, Laczmański L, Jedrzejuk D, Trzmiel-Bira A, Szmigiero L. ADRB3 and PPAR $\gamma 2$ gene polymorphisms and their association with cardiovascular disease risk in postmenopausal women. Climacteric. 2013 Aug;16(4):473-8. doi: 10.3109/13697137.2012.738721.

32. Tariq K, Malik SB, Ali SH, Maqsood SE, Azam A, Muslim I, et al. Association of Pro12Ala polymorphism in peroxisome proliferator activated receptor gamma with proliferative diabetic retinopathy. Mol Vis. 2013;19:710-7.

33. Qi Q, Hu FB. Genetics of type 2 diabetes in European populations. J Diabetes. 2012 Sep;4(3):203-12. doi: 10.1111/j.1753-0407.2012.00224.x.

34. Malecki MT, Frey J, Klupa T, Skupien J, Walus M, Mlynarski W, Sieradzki J. The Pro12Ala polymorphism of PPARgamma2 gene and susceptibility to type 2 diabetes mellitus in a Polish population. Diabetes Res Clin Pract. 2003 Nov;62(2):105-11. doi: 10.1016/s0168-8227(03)00164-5.

35. Isakova ZhT, Talaybekova ET, Zhyrgalbekova BZh, et al. [Intergenic interactions and the contribution of polymorphic loci of genes KCNJ11, ADIPOQ, omentin, leptin, TCF7L2 and PPARg to the development of type 2 diabetes in Kyrgyz population: preliminary results of a case-control study using MDR analysis]. Endocrinology Problems. 2018; 64 (4): 216225. doi: 10.14341 / probl8344. [Article in Russian].

36. Nikitin AG, Potapov VA, Brovkin AN, Lavrikova EYu, Khodyrev DS, Shamkhalova MSh, et al. [Association of polymorphic markers of FTO, KCNJ11, SLC30A8 and CDKN2B genes with type 2 diabetes]. Molecular Biology. 2015; 49: (1): 119-128 DOI: 10.7868 / S0026898415010115. [Article in Russian].

37. Ievleva KD, Bairova TA, Sheneman EA, Ayurova $\mathrm{ZhG}$, Balzhieva VV, Novikova EA, et al. [Protective effect of the G-allele of the PPARG2 rs1801282 polymorphism on overweight and obesity in Mongoloid adolescents]. Journal. Med Biol Research 2019; 7 (4): 452-463. doi: 10.17238 / issn2542-1298.2019.7.4.452. [Article in Russian].

38. Silko YuV, Nikonova TV, Ivanova ON, Stepanova SM, Shestakova MV, Dedov II. [Association of rs7903146 polymorphism of the TCF7L2 gene with low concentrations of autoantibodies in latent autoimmune diabetes in adults (LADA)]. Diabetes 2016;19(3):199-203. doi: 10.14341 / DM2003418-2. [Article in Russian].

39. Potapov VA, Chistiakov DA, Shamkhalova MS, Shestakova MV, Nosikov VV. TCF7L2 rs12255372 and SLC30A8 rs13266634 confer susceptibility to type 2 diabetes in a Russian population. Diabetes and Metabolic Syndrome Clinical Research Review 2009; 3(4): 219-223.

40. Ensembl project [Internet]. Available from: https://www. ensembl.org/index.html_ 